\title{
L-Cystine Diamides as L-Cystine Crystallization Inhibitors for Cystinuria
}

\author{
Longqin $\mathrm{Hu},{ }^{*}, \dagger$ Yanhui Yang, ${ }^{\dagger}$ Herve Aloysius, ${ }^{\dagger}$ Haifa Albanyan, ${ }^{\dagger}$ Min Yang, ${ }^{\ddagger}$ Jian-Jie \\ Liang, ${ }^{\S}$ Anthony Yu," Alexander Shtukenberg," Laura N. Poloni," Vladyslav \\ Kholodovych, ${ }^{+}{ }^{\perp}$ Jay A. Tischfield, ${ }^{\ddagger}$ David S. Goldfarb ${ }^{\#}$, Michael D. Ward," Amrik Sahota ${ }^{\ddagger}$ \\ †Department of Medicinal Chemistry, Ernest Mario School of Pharmacy, Rutgers, The State University of New Jersey, \\ Piscataway, New Jersey o8854 \\ ‡Department of Genetics, Rutgers, The State University of New Jersey, Piscataway, New Jersey o8854 \\ §Dassault Systemes BioVIA Corp, San Diego, CA 92121 \\ "Molecular Design Institute, Department of Chemistry, New York University, New York, NY 10003 \\ \#Nephrology Division, NYU Langone Medical Center, New York, NY 10016 \\ ${ }^{\perp}$ High Performance and Research Computing, Office of Advanced Research Computing, Rutgers, The State University \\ of New Jersey, Piscataway, New Jersey 08854
}

\section{SUPPORTING INFORMATION}

\section{CONTENTS}

\section{o Supplemental Experimental Details}

- Fluorescence assay for the inhibition of L-cystine crystal formation

- AFM crystal growth experiments

- Chemical stability measurement

- In vivo activity in mouse model of cystinuria

- Measurement of compound concentration in urine

\section{o Spectroscopic Data for New Compounds:}

- $\quad{ }^{1} \mathrm{H}$ NMR of I-Cystine bismorpholide (CDMOR, LH707, 1a)

- ${ }^{13} \mathrm{C}$ NMR of I-Cystine bismorpholide (CDMOR, LH707, 1a)

- $\quad{ }^{1} \mathrm{H}$ NMR of I-cystine bis(N'-methylpiperazide) (CDNMP, LH708, 1b)

- ${ }^{13} \mathrm{C}$ NMR of I-cystine bis(N'-methylpiperazide) (CDNMP, LH708, 1b) 


\section{Supplemental Experimental Details}

\section{Fluorescence assay for the inhibition of L-cystine crystal formation}

Formation of supersaturated solution. $21 \mathrm{mg}$ of L-cystine was dissolved in $30 \mathrm{~mL}$ of Millipore water ( 3 mM) under reflux at $100{ }^{\circ} \mathrm{C}$ for 20 min until the L-cystine was completely dissolved. The supersaturated solution was then allowed to cool slowly with stirring for $75 \mathrm{~min}$.

Construction of standard curves. L-Cystine ( $5 \mathrm{mg}$ ) was dissolved in Millipore water (34.7 $\mathrm{mL}$ ) to form a $0.6 \mathrm{mM}$ solution as a stock solution. Then, L-cystine solution was diluted to 0.4, 0.3, 0.2, 0.1, 0.05 mM solution. $10 \mathrm{uL}$ of each L-cystine solutions, $90 \mathrm{uL}$ of $0.1 \mathrm{M}$ dibasic sodium phosphate solution, and 10 uL of DTT solution (12.5 mM) were mixed at r.t. for $10 \mathrm{~min}$, before the addition of $10 \mathrm{uL}$ of iodoacetic acid $(100 \mathrm{mM})$ and continued incubation at r.t. for an additional $15 \mathrm{~min}$. This was then followed by the addition of $10 \mathrm{uL}$ of OPA (100 $\mathrm{mM}$ in methanol) and $10 \mathrm{uL}$ of NBC (100 $\mathrm{mM}$ in methanol). The derivatization was allowed to proceed for 3 min before 40 uL of the mixture was placed in a 384-well plate and read at Ex $355 \mathrm{~nm} / \mathrm{Em} 460 \mathrm{~nm}$. The standard curve was repeated for each set of experiments and used to calculate the concentration of L-cystine in each sample.

Determination of L-cystine concentration. All test compounds were dissolved in water to form $10 \mathrm{mM}$ stock solution. Five uL of each solution was added to $500 \mathrm{uL}$ L-cystine supersaturated solution. The mixtures were allowed to stand at $25^{\circ} \mathrm{C}$ for $72 \mathrm{~h}$. At the end of incubation, the mixtures were centrifuged at 10,ooo rpm for $4 \mathrm{~min}$ and the supernatants were diluted 2-fold for concentration measurement. Each diluted mixture (10 uL), o.1 M dibasic sodium phosphate solution $(90 \mathrm{uL})$, and $10 \mathrm{uL}$ of DTT solution $(12.5 \mathrm{mM})$ were mixed at r.t. for $10 \mathrm{~min}$, before the addition of $10 \mathrm{uL}$ of iodoacetic acid (100 $\mathrm{mM})$ and continued incubation at r.t. for an additional $15 \mathrm{~min}$. Derivatization was performed by the addition of $10 \mathrm{uL}$ of OPA (100 $\mathrm{mM}$ in methanol) and $10 \mathrm{uL} \mathrm{of} \mathrm{NBC} \mathrm{(100} \mathrm{mM} \mathrm{in}$ methanol) for $3 \mathrm{~min}$. $40 \mathrm{uL}$ of the derivatized mixture was plated in a 384-well plate and fluorescence was read at Ex $355 \mathrm{~nm} / \mathrm{Em} 460 \mathrm{~nm}$ to derive the concentrations of the original mixtures.

\section{AFM crystal growth experiments}

Preparation of L-cystine crystals. Hexagonal L-cystine plate crystals were formed by refluxing $70 \mathrm{mg}$ of L-cystine in $100 \mathrm{~mL}$ of deionized water $(3 \mathrm{mM})$ for 30 minutes at $100{ }^{\circ} \mathrm{C}$ while stirring. The solution was then cooled at room temperature while stirring for 70 minutes, split into two $50 \mathrm{~mL}$ aliquots in $100 \mathrm{~mL}$ beakers, and stored at room temperature for 72 hours. All crystals used for AFM crystal growth experiments were collected via vacuum filtration (Whatman Grade 4 filters, 20-25 $\mu$ m pores) and air dried.

Hexagonal L-cystine plate crystals were formed using the same method described above. A 2 mM L-cystine solution for the fluid cell flow was prepared by refluxing $48 \mathrm{mg}$ of L-cystine in $100 \mathrm{~mL}$ deionized water at $100{ }^{\circ} \mathrm{C}$ for 30 minutes. The solution was then cooled for 70 minutes and split into a $25 \mathrm{~mL}$ aliquot and a $75 \mathrm{~mL}$ aliquot. The $75 \mathrm{~mL}$ aliquot was used to inject into the fluid cell for L-cystine crystal growth measurements without inhibitor additives. The $25 \mathrm{~mL}$ aliquot was injected with 1a or $\mathbf{1 b}$ to produce 15 , 30, or $45 \mu \mathrm{M}$ inhibitor solutions. Inhibitor stock solutions were prepared by creating $2 \mathrm{mg} / \mathrm{mL}$ stock solutions in $5 \mathrm{~mL}$ vials. AFM samples were prepared using Norland optical adhesive (type 81) on an AFM specimen disc ( $15 \mathrm{~mm}$ diameter). The adhesive was first cured under UV radiation $(\lambda=365 \mathrm{~nm}$ ) for 1 minute and then pressed against large L-cystine plate crystals that were isolated using a needlepoint and an optical microscope. The sample was then cured for 12 minutes and excess crystals were removed by lightly blowing air over the sample. All in situ AFM experiments were performed on a Veeco Multimode ${ }^{\mathrm{TM}}$ Scanning Probe Microscope using the "J" scanner (maximum scan size - 85-100 $\mu \mathrm{m}$ ) in a fluid cell in contact mode. Solution was pushed into the cell at $10 \mathrm{~mL} / \mathrm{hr}$ by a $24 \mathrm{~mL}$ syringe at automated rates using a Razel syringe pump. Bruker V shaped SiN AFM tips were used for measurements (model NP-10: radius of curvature $=20$ $\mathrm{nm}$, spring constant $=0.12 \mathrm{~N} / \mathrm{m}$ ). Step distances were measured using the program user interface and all step velocities and step spacing values were calculated as mean \pm standard deviation.

\section{Chemical stability measurement}

Solutions of $100 \mu \mathrm{M}$ test compounds in phosphate buffered saline were incubated at $37^{\circ} \mathrm{C}$. Aliquots $(20 \mu \mathrm{L})$ were taken at different time intervals and frozen at $-20^{\circ} \mathrm{C}$. The aliquots were diluted 5 -fold with water to $100 \mu \mathrm{L}$ prior to analysis with LC-MS/MS in positive MRM mode in the case of CDME $(269.5 \rightarrow 134.4)$ and 12 (379.5 $\rightarrow 189.6)$ or acetylation in the case of $\mathbf{1 b}$ with $\mathbf{1} \mathrm{mM} \mathrm{Ac}_{2} \mathrm{O}$ at r.t for $30 \mathrm{~min}$ followed by analysis by LC-MS/MS in positive MRM mode $(489.2 \rightarrow 101.0)$ on an API 3000 (AB Sciex, Framingham, MA). Chromatographic separation was achieved with a $2 \times 20 \mathrm{~mm}, 5 \mu \mathrm{m}, \mathrm{C}_{4}$ reversed phase column using a water/methanol gradient containing $0.1 \%$ formic acid (5-90\%) at a flowrate of $250 \mu \mathrm{L} / \mathrm{min}$. The standard curves were constructed with standards of CDME, $\mathbf{1 a}$ and $\mathbf{1 b}$, respectively. 


\section{In vivo activity in mouse model of cystinuria}

Slczar knockout mice in a mixed $129 / \mathrm{C}_{57} \mathrm{BL} 6$ background were used in the studies described here. We selected two-month old knockout male mice for treatment. Mice at this age exhibit crystalluria but very few or no bladder stones whereas approximately $50 \%$ of three-month-old mice exhibit stones, making this the ideal window to assess the effects of treatment. Most male mice over age six months have bladder stones and some have kidney stones as well. Female knockout mice have crystalluria but no stones until age over 12 months. Mouse genotypes and gender were determined by PCR amplification of tail DNA. Based on previous observations, Slczar heterozygotes have no apparent phenotype so they were used in place of wild-type mice as needed. Animal studies were conducted in accordance with Rutgers University IACUC policies.

Test compound solutions were prepared fresh daily and $200 \mu \mathrm{L}$ was administered at a dose of $29.3 \mu \mathrm{mol} / \mathrm{Kg}$ to Slczar knockout male mice (body weight $20 \mathrm{~g}$ ) by gavage daily for four weeks using a $20 \mathrm{G}$ disposable flexible plastic feeding needle with a soft tip (Model FTP-20-30, Instech Laboratories, Inc., Plymouth Meeting, PA). The control group received daily $200 \mu \mathrm{L}$ of water only. Urine samples $(0.5$ to $1 \mathrm{ml})$ were collected by placing the mice in metabolic cages for four hours or longer.

\section{Measurement of compound concentration in urine}

Levels of compounds in urine were quantified using LC-MS/MS in positive MRM mode (1a, 379.0 $\rightarrow 188.9$; $\mathbf{1 b}$, $203.1 \rightarrow 101.3$ ) on a Transcend LX2 system (Thermo Fisher, Waltham, MA) coupled to an API 4000 (AB Sciex, Framingham, MA). Chromatographic separation was achieved with a 2.1x50 mm, $5 \mu \mathrm{m}$ HILIC column (Waters Corporation, Huntingdon Valley, PA) using a water (A)/ACN (B) mobile phase system containing $0.1 \%$ formic acid $(\mathrm{v} / \mathrm{v})$. The gradient was performed at a total flow rate of $750 \mu \mathrm{L} / \mathrm{min}$ as follows, $95 \%$ B from o to $1.5 \mathrm{~min}$, 95 to $5 \%$ B from 1.5 to $2.2 \mathrm{~min}, 5 \%$ B from 2.2 to $2.7 \mathrm{~min}, 5$ to $95 \%$ B from 2.7 to $2.8 \mathrm{~min}, 95 \%$ B from 2.8 to $4.3 \mathrm{~min}$. 
Spectroscopic Data for New Compounds:

- $\quad{ }^{1} \mathrm{H}$ NMR of L-Cystine bismorpholide (CDMOR, LH707, 1a)

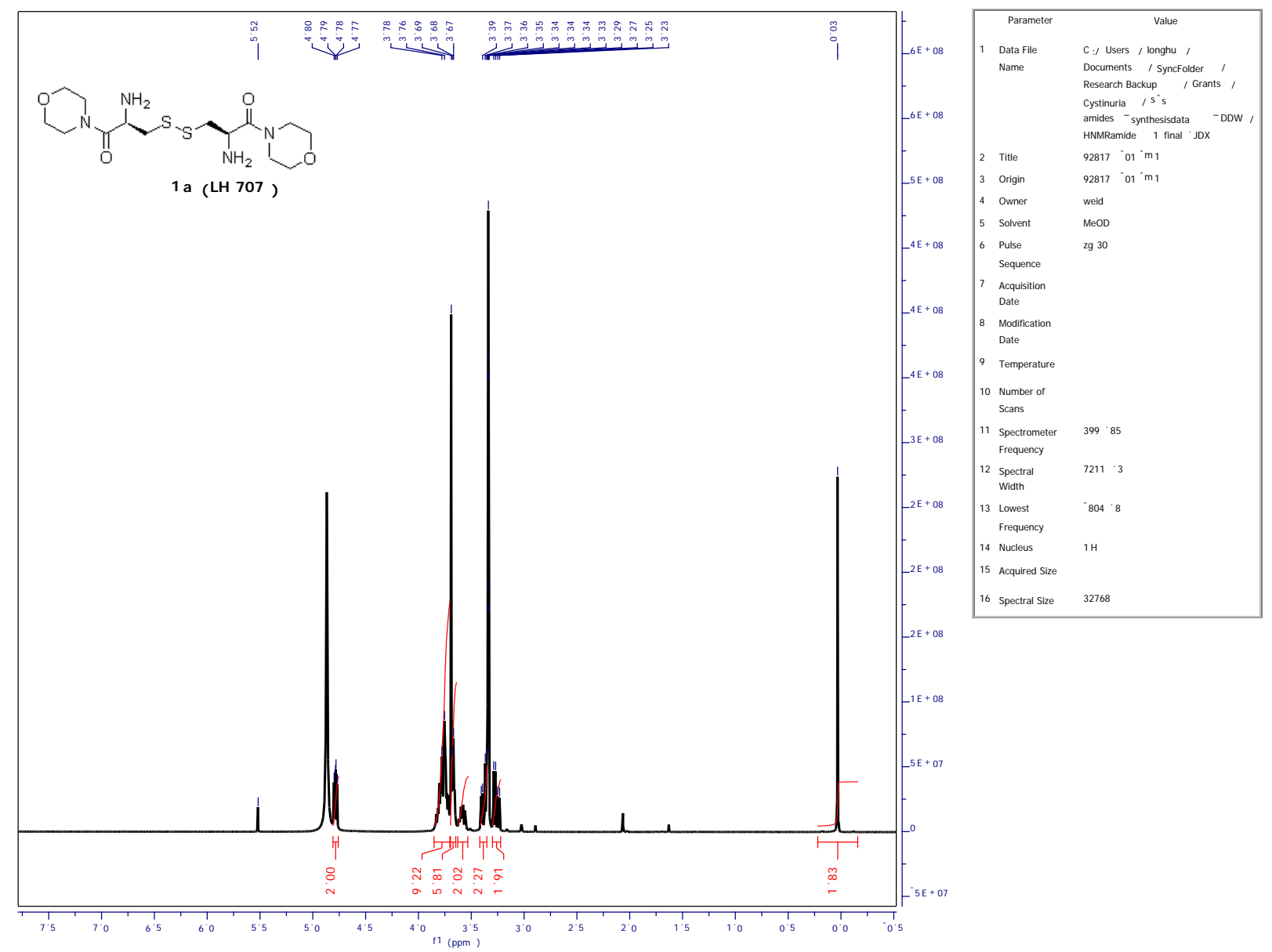


- $\quad{ }^{13}$ C NMR of L-Cystine bismorpholide (CDMOR, LH707, 1a)

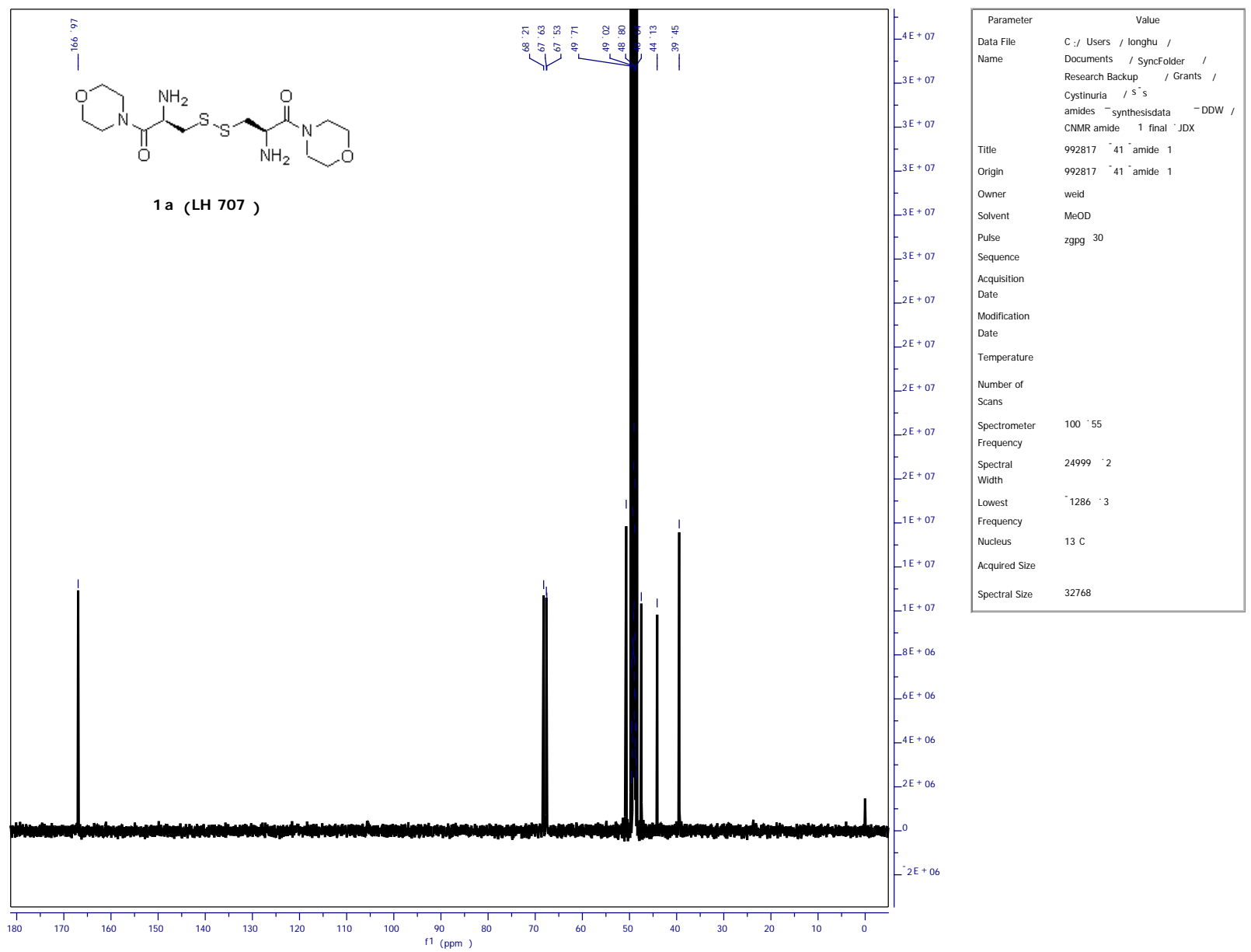


- $\quad{ }^{1} \mathrm{H}$ NMR of L-cystine bis( $\mathrm{N}^{\prime}$-methylpiperazide) (CDNMP, LH708, 1b)

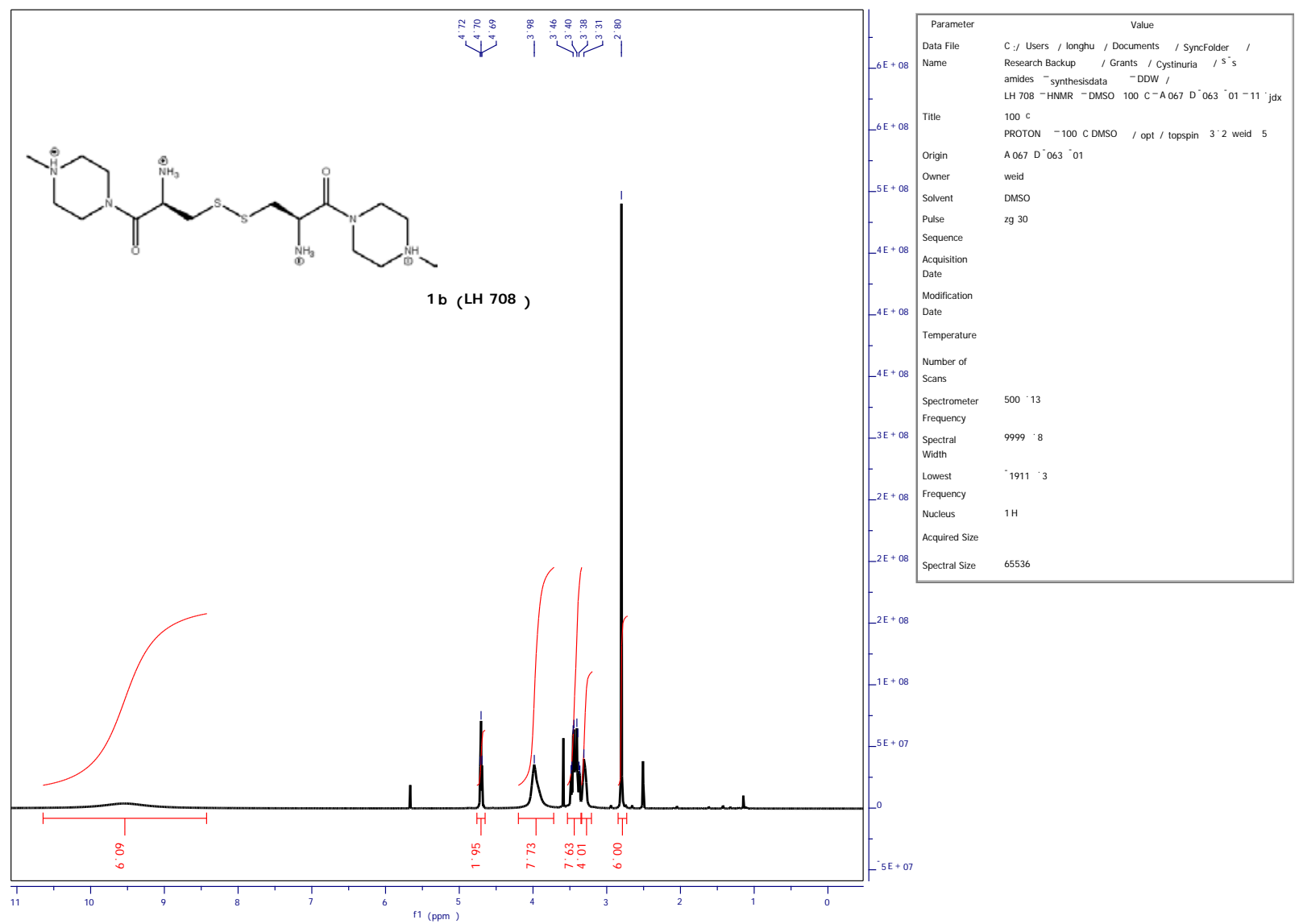


- $\quad{ }^{13} \mathrm{C}$ NMR of L-cystine bis(N'-methylpiperazide) (CDNMP, LH708, 1b)

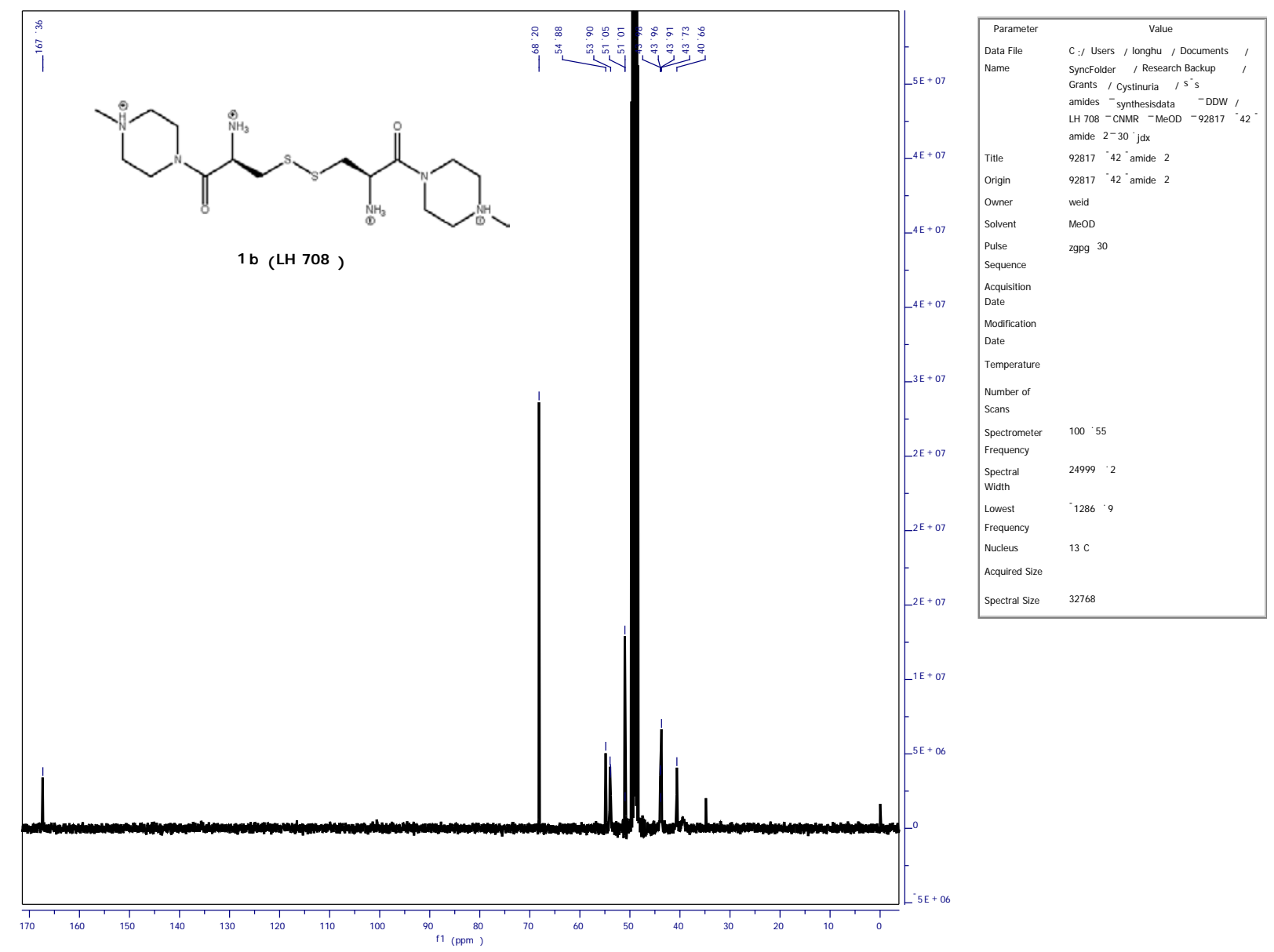

